5. Болгов В.И., Евсюкова Т.В., Козина В.В., Пустынников М.А. Методика первичного сортоизучения цветочных культур. - М.: ВНИИЦиСК, 1998. - 40 с.

6. Пугачева Г.М., Соколова М.А., Мартынова В.В. Методика первичного сортоизучения лилий. - Мичуринск; Воронеж: Кварта, 2015. - 28 с. - ISBN 978-5-89609-398-5.

7. Программа и методика отдаленной гибридизации плодовых и ягодных культур. Мичуринск, 1972. - $141 \mathrm{c.}$

8. Соколова М.А. Подбор исходного материала для селекции азиатских лилий // Научно-практические основы ускорения импортозамещения продукции садоводства: мат. науч.-практ. конф. - Мичуринск, 2017. - С. 69-73. - ISBN 978-5-9500762-6-8.

\title{
SOME FEATURES OF ASIATIC LILIES HYBRIDIZATION
}

\author{
Sokolova M. A. \\ Federal State Budgetary Scientific Institution \\ "I. V. Michurin Federal Scientific Centre", \\ Michurinsk, Russia, e-mail: marina-111012@rambler.ru
}

The paper presents some results on hybridization of Asiatic lily hybrids. A long-term comprehensive study of Asiatic lilies from domestic and foreign breeding allowed us to identify the sources of valuable traits. To obtain a new breeding material the hybridization involved cultivars, which were characterized by a complex of decorative and economically valuable features. A brief description of the original parent forms is provided in the paper. The analysis of the performed crossing combinations is also given. The new breeding material was received in the amount of 4243 hybrid seeds of Asiatic lilies.

Key words: lilies, cultivar, breeding, hybridization, Asiatic lily hybrids.

УДК 635.9+631.52 (262.5+479)

doi: 10.31360/2225-3068-2020-74-76-84

\section{СРОКИ ЦВЕТЕНИЯ СОРТОВ И ГИБРИДОВ ХРИЗАНТЕМЫ САДОВОЙ (CHRYSANTHEMUM $\times$ HORTORUM) В УСЛОВИЯХ ЧЕРНОМОРСКОГО ПОБЕРЕЖЬЯ КАВКАЗА}

Якушина Л. Г.

\author{
Федеральное государственное бюджетное учреждение науки \\ «Федеральный исследовательский иентр «Субтропический научный иентр \\ Российской академии наук», \\ 2.Сочи, Россия, e-mail: -vishnya584@yandex.ru
}

Изучены стадии цветения корзинок 9 сортов, 7 гибридов коллекции хризантемы садовой (Chrysanthemum $\times$ hortorum Bailey) ФИЦ СНЦ РАН. По времени прохождения стадий развития корзинок все изученные формы хризантемы поделены на три группы: раннецветущие (цветение с 18-25 октября по 15-22 ноября); со средними сроками цветения (цветение с 25-30 октября по 20-30 ноября), позднецветущие (цветение с 29 октября - 5 ноября по 20-26 декабря). Выявлены формы с самыми длительными сроками цветения: 'Балун', ‘Этруско', ‘Annecy White', 'Zembla Lime', K-141-1. Хризантемы в условиях Черноморского побережья 
Глава 3. Селекция и семеноводство

Кавказа преимущественно цветут с середины октября до середины декабря, а некоторые ('Этруско', 'Annecy White', Ж-108-2) до конца декабря, когда продолжительность светового дня становится менее 11 часов. Закладка бутонов начинается при сокращении светового дня до 12 часов. Цветение хризантем зависит и от температурного фактора.

Ключевые слова: хризантема садовая (Chrysanthemum $\times$ hortorum), длина светового дня, температура, сроки цветения, исходный селекционный материал.

Среди оранжерейных цветочных культур важное место принадлежит хризантеме - древнейшей цветочной культуре, которая возделывается со времен Конфуция (551-479 гг. до н.э.) [2, 9, 13].

В современном коммерческом цветоводстве объём производства хризантем уступает только розам и луковичным. Их выращивают на срезку и в качестве горшечных растений, в последние годы хризантема стала очень популярной в наружном и внутреннем озеленении $[2,7,15]$.

Изучению сроков цветения хризантем и управляемости цветением посвящён ряд исследований. При этом отмечается, что в зависимости от условий и местного генофонда они имеют свои особенности, которые требуют специального изучения $[5,8,9]$.

Предполагают, что садовая хризантема, прародителями которой являются дикорастущие дендрантемы с простыми ромашковидными соцветиями, ведёт свое начало из Китая и существует в культуре около трёх тысячелетий. В то время выращивали формы с золотисто-жёлтыми соцветиями, которые мало чем отличались от дикорастущих видов. Их разводили не только ради красоты цветов, но использовали в пищу и в качестве лекарства. В результате длительной селекционной работы получено множество сортов, превосходящих по декоративности исходные дикорастущие формы, чрезвычайно разнообразных по строению, размеру и окраске соцветий $[10,11]$.

В оранжереях зоны умеренного климата выращивают сорта, цветущие осенью и ранней зимой. Основными исходными видами при выведении современных садовых хризантем послужили дендрантема индийская (Dendranthema indicum) и дендрантема шелковицелистная (Dendranthema morifolium), однако в многовековой селекции использовались и другие виды $[2,20]$.

История изучения культуры хризантемы в Федеральном государственном бюджетном учреждении науки «Федеральный исследовательский центр «Субтропический научный центр Российской академии наук» (ФИЦ СНЦ РАН) насчитывает более 45 лет. За этот период в исследовании участвовало более 150 сортов хризантемы крупноцветной и более 40 сортов хризантемы мелкоцветной $[6,18]$. 
Первую научно-исследовательскую работу в 1972-1975 гг. по разработке промышленного сортимента и технологии выращивания крупноцветковых хризантем в условиях закрытого грунта проводил Б. В. Датченко под руководством доктора с.-х. наук В. В. Воронцова [18]. В дальнейшем эти исследования продолжила Л. С. Абдуллаева. С мелкоцветковой хризантемой начали работать в 1986 г. под руководством кандидата с.-х. наук Г. К. Солнцева, а с 1995 г. кандидата с.-х. наук Н. П. Козьменко [18].

Параллельно, изучением садовых хризантем с целью дальнейшего использования в селекции занималась канд. с.-х. наук В. С. Мохно [18].

Селекционные исследования на хризантеме садовой (Chrysanthemum $\times$ hortorum) в ФИЦ СНЦ РАН проводятся с 2006 г. В результате проведённых скрещиваний с 2006 по 2016 год создано и внесено в Реестр селекционных достижений РФ 12 сортов: 'Южная', 'Симфония', 'Юность', ‘Альпика', 'Камея', 'Ноктюрн', 'Розовый Зефир', 'Солнечная', ‘Зимнее утро’, ‘Элен', 'Кадриль', 'Карнавал' [9]. Продолжается изучение гибридного фонда и выделение перспективных форм как кандидатов в сорта.

Время прохождения стадий у большинства форм хризантемы зависит от длины светового дня и температуры окружающей среды. Эти особенности важно учитывать при подборе селекционного материала, так как сроки цветения, продолжительность цветения, возможность управлением цветения являются характерными особенностями будущего сорта. Для промышленного производства прохождение стадий тоже необходимо учитывать, так как на стадии закладки бутонов вносятся калийные удобрения, а в начале цветения хризантем - фосфорные удобрения. Продолжительность бутонизации позволяет оценить возможность круглогодичного выращивания данной культуры $[4,20]$. Продолжительность цветения является важной характеристикой сорта.

Селекционеры пытаются получить формы хризантем, обладающие сильным ростом и быстрой реакцией на изменение продолжительности дня, выдерживающие большой диапазон температуры, устойчивые к низкой освещённости в осенне-зимний период и дающие цветы, пригодные для транспортирования на дальние расстояния [20].

Бутоны можно доращивать вне оранжереи. Срезку проводят в стадии окрашенных бутонов и помещают побеги в питательный раствор. При температуре 22-24 ${ }^{\circ} \mathrm{C}$ бутоны полностью распускаются через 5-7 дней [1].

Цель исследований: изучение периода бутонизации и сроков цветения исходного селекционного материала хризантемы коллекции ФИЦ СНЦ РАН в условиях Черноморского побережья Кавказа.

Объекты и методы. Исследования проводили в 2018-2019 гг. на опытной базе ФИЦСНЦРАН в с. Раздольное в условиях необогреваемых теплиц. 
Глава 3. Селекция и семеноводство

Объекты - 9 сортов и 7 гибридов хризантемы садовой (Chrysanthemum $\times$ hortorum Bailey). Изучали коллекцию по методике проведения испытаний на отличимость, однородность и стабильность хризантемы (многолетней) Chrysanthemum spec. [7]. Данные фенологических наблюдений вносили в таблицы. Отмечали стадии развития корзинок от вегетативного апекса (0) до цветущих корзинок (10). Для наглядности сравнили показатели трёх стадий: закладка цветочного бутона (2 - цветочный бутон виден, но менее 10 мм в диаметре), распускание цветов (6 - цветки распускаются (язычковые)), и цветение растений (8 - внешние язычковые цветки полностью раскрыты - «открытый цветок»).

Климатические условия района исследований характерны для зоны влажных субтропиков. Средняя годовая температура воздуха составляет $+14,1{ }^{\circ} \mathrm{C}$. Температура января и февраля $-+6,0 \ldots 6,1{ }^{\circ} \mathrm{C}$, июля и августа $-+23,2 \ldots 23,6^{\circ} \mathrm{C}$. Средний абсолютный минимум температуры достигает $-7^{\circ} \mathrm{C}$. Регион характеризуется выпадением большого количества осадков, средняя годовая норма составляет 1635 мм, преимущественно ливневого характера. Осадки в виде снега в прибрежной зоне явление редкое, снежный покров неустойчивый [14]. Уникальные климатические условия достаточно благоприятны для выращивания многих цветочно-декоративных культур, в том числе и хризантемы.

Результаты и их обсуждение. Хризантема садовая (Chrysanthemum $\times$ hortorum Bailey) относится к растениям короткого дня, её цветение приходится на конец сентября - декабрь. Сокращение светового периода, т. е. увеличение длительного периода темноты [20], стимулирует формирование соцветий (бутонизацию) у хризантемы и тем самым влияет на начало цветения. Длина дня, вызывающая закладку бутонов и цветение у разных сортов, неодинакова $[2,12,20]$.

Важным признаком для определения пригодности хризантем для круглогодичной культуры является продолжительность периода бутонизации, который, как известно, начинается с установления в оранжерее коротких дней [20].

В результате проведённых наблюдений установлено, что средняя температура воздуха весной за два года наблюдений составила $+14,8^{\circ} \mathrm{C}$, в январе 2019 г. была отмечена минимальная температура $0{ }^{\circ} \mathrm{C}$ (табл. 1).

Для закладки бутонов оптимальная температура должна быть $18-22{ }^{\circ} \mathrm{C}$, для цветения $-10{ }^{\circ} \mathrm{C}$.

В нашем опыте температура была выше оптимальной для закладки бутонов в среднем на $3-7{ }^{\circ} \mathrm{C}$ в августе и на верхней границе нормы в сентябре, для цветения на 6-10 ${ }^{\circ} \mathrm{C}$ выше - в октябре и ноябре. Причём 2019 г. был теплее предыдущего в среднем на 3-5 градусов, что 
сказалось на сроках закладки бутонов. Период бутонизации образцов нашей коллекции начинается со второй декады сентября, в отдельные годы - в начале октября (табл. 2). Период бутонизации у большинства изученных сортов и гибридов в 2019 г. начался раньше на 2-14 дней. Цветение большинства гибридов и сортов началось раньше в 2019 г. на 2-7 дней. У сорта 'Etrusko', в отличие от других сортов и гибридов, фенологические стадии проходили иначе: в более тёплом году закладка бутонов и цветение происходили позднее на 25 и 10 дней соответственно. У сорта 'Annecy White' продолжительность цветения может сильно варьировать от 24 до 34 дней.

Таблииа 1

Среднемесячная температура воздуха в 2018-2019 гг., ${ }^{\circ} \mathrm{C}$

\begin{tabular}{|c|c|c|c|c|c|c|c|c|c|c|c|c|c|c|c|}
\hline Месяц &  &  &  & 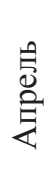 & $\sum^{2 / 5}$ & 鱼 & $\stackrel{\text { s }}{\underline{5}}$ & 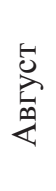 & 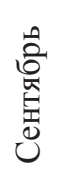 & 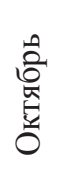 &  & 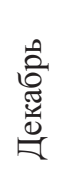 & 좀 & 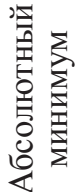 & 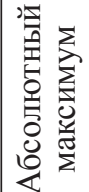 \\
\hline 2018 г. & $\overrightarrow{6}$ & $\stackrel{2}{r}$ & $\hat{a}$ & $\stackrel{n}{\simeq}$ & $\stackrel{2}{=}$ & $\overrightarrow{\tilde{d}}$ & $\vec{d}$ & î & $\begin{array}{l}0 \\
\vec{N}\end{array}$ & $\ddot{0}_{0}$ & $\stackrel{n}{=}$ & $\approx$ & $\vec{n}$ & T & \\
\hline 2019 г. & $\vec{\sigma}_{\sigma}$ & $\hat{\sigma}$ & $\hat{0}$ & ${ }_{0}^{0}$ & กิ & $\overrightarrow{\hat{N}}$ & $\stackrel{+}{+}$ & $\stackrel{\infty}{n}$ & 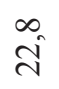 & $\stackrel{\vec{v}}{\vec{v}}$ & $\hat{\sigma}$ & $\overrightarrow{\mathrm{a}}$ & $\stackrel{N}{\infty}$ & 0 & \\
\hline $\begin{array}{c}\text { Средние } \\
\text { значения }\end{array}$ & $\stackrel{\infty}{\sim}$ & के & กิ & $\stackrel{m}{ \pm}$ & $\hat{\sigma}$ & $\stackrel{0}{ \pm}$ & $\stackrel{\text { ñ }}{+}$ & $\tilde{n}$ & તิ & $\hat{\infty}$ & $\stackrel{\circ}{ \pm}$ & $\hat{\sigma}^{\prime}$ & $\hat{\sigma}$ & & \\
\hline
\end{tabular}

Температура является важным фактором для формирования корзинок (табл. 2). Продолжительность цветения у разных сортов и гибридов может меняться как в сторону увеличения, так и в сторону уменьшения.

В результате проведённых фенологических наблюдений установлено, что бутонизация сортов и гибридов хризантем коллекции ФИЦ СНЦ РАН составляет 1-4 недели, тогда как некоторые авторы отмечают, что данный период значительно длиннее. Так, В. Н. Шмыгун [20] отмечает, что бутонизация может длиться от 9 до 13 недель. Наблюдается следующая закономерность: сорта, которые развиваются в условиях слабой освещённости - с ноября по февраль - имеют длинный период бутонизации, около 3-4 месяцев, а у сортов, которые развиваются при хорошей освещённости - с мая по сентябрь - период бутонизации равен всего лишь 2-2,5 месяцам [20].

Анализ исходного селекционного материала хризантемы садовой (Chrysanthemum $\times$ hortorum) коллекции ФИЦ СНЦ РАН по срокам цветения позволил выделить три фенологические группы в зависимости от длины светового дня: 
Глава 3. Селекция и семеноводство

гибриды раннего срока цветения: Ж-116-2; К-104-1; Ж-10-4; И-181-1 составляют $25 \%$ от изученных растений коллекции, цветение их начинается с 18-25 октября по 15-22 ноября;

сорта и гибриды среднего срока цветения: 'Zembla Lime'; 'Annecy White'; ‘Балун’; ‘Золотая Нива'; ‘Tiger Red'; К-141-1; Ж-23-5 - цветение с 25-30 октября по 20-30 ноября, представлены большим количеством сортов и гибридов от изученных - $44 \%$;

сорта позднего срока цветения: 'Mona Lisa White'; 'Princess Amgard bronze'; 'Princess Amgard bronze'; ‘Этруско'; Ж-108-2 - 31 \% (цветут с 29 октября - 5 ноября по 20-26 декабря).

Таблица 2

Сравнение сроков цветения

некоторых форм хризантемы в 2018-2019 гг.

\begin{tabular}{|c|c|c|c|c|c|c|c|c|}
\hline \multirow{3}{*}{$\begin{array}{c}\text { Форма } \\
\text { (сорт, гибрид) }\end{array}$} & \multicolumn{6}{|c|}{ Фенологические фазы } & \multirow{2}{*}{\multicolumn{2}{|c|}{$\begin{array}{c}\text { Продолжи- } \\
\text { тельность цве- } \\
\text { тения }\end{array}$}} \\
\hline & \multicolumn{2}{|c|}{ Стадия 2} & \multicolumn{2}{|c|}{ Стадия 6} & \multicolumn{2}{|c|}{ Стадия 8} & & \\
\hline & 2018 & 2019 & 2018 & 2019 & 2018 & 2019 & 2018 & 2019 \\
\hline ‘Балун' & 01.10 & 05.10 & 23.10 & 18.10 & 02.11 & 26.10 & 28 & 26 \\
\hline 'Mona Lisa White' & 15.10 & 03.10 & 20.10 & 15.10 & 02.11 & 29.10 & 17 & 25 \\
\hline $\begin{array}{l}\text { 'Princess Amgard } \\
\text { bronze' }\end{array}$ & 09.10 & 06.10 & 22.10 & 16.10 & 05.11 & 29.10 & 23 & 23 \\
\hline 'Princess Amgard red' & 09.10 & 06.10 & 22.10 & 16.10 & 05.11 & 29.10 & 23 & 24 \\
\hline 'Золотая Нива' & 09.10 & 04.10 & 20.10 & 12.10 & 24.10 & 21.10 & 28 & 25 \\
\hline 'Etrusko' & 17.09 & 12.10 & 25.10 & 26.10 & 29.10 & 9.11 & 20 & 23 \\
\hline 'Annecy White' & 30.09 & 25.09 & 10.10 & 03.10 & 25.10 & 21.10 & 24 & 34 \\
\hline 'Zembla Lime' & 17.09 & 28.09 & 24.10 & 5.10 & 26.10 & 19.10 & 20 & 26 \\
\hline 'Tiger Red' & 23.09 & 25.09 & 29.10 & 11.10 & 2.11 & 25.10 & 24 & 21 \\
\hline Ж-116-2 (№ 80) & 01.10 & 25.09 & 12.10 & 05.10 & 28.10 & 18.10 & 25 & 22 \\
\hline К-104-1 (№ 155) & 29.09 & 27.09 & 10.10 & 07.10 & 25.10 & 19.10 & 26 & 23 \\
\hline Ж-10-4 (№ 23) & 07.10 & 02.10 & 15.10 & 05.10 & 25.10 & 19.10 & 26 & 22 \\
\hline И-181-1 & 07.10 & 03.10 & 15.10 & 09.10 & 23.10 & 19.10 & 27 & 21 \\
\hline К-141-1 (№ 69) & 10.10 & 02.10 & 18.10 & 10.10 & 30.10 & 23.10 & 26 & 26 \\
\hline Ж-108-2 (№ 142) & 09.10 & 01.10 & 02.11 & 03.11 & 15.11 & 13.11 & 25 & 24 \\
\hline Ж-23-5 & 09.10 & 25.09 & 15.10 & 05.10 & 24.10 & 20.10 & 28 & 24 \\
\hline
\end{tabular}

В условиях защищённого грунта бутонизация у ранних гибридов и сортов начинается при длине дня 12-13 часов, у средних - при длине дня 11-12 часов (рис. 1). Для закладки бутонов поздним гибридам и сортам необходим световой день 11 часов (рис. 1). 
Очень важно вести отбор селекционного материала хризантемы, устойчивого к высоким температурам нашего региона.

Цеханович С. В., проводившая исследования в Центральном ботаническом саду НАН Беларуси, отмечает, что цветение начинается с конца сентября у раннецветущих сортов хризантем [19]. В Молдове цветение хризантем также наступает у раннецветущих групп в сентябре [3]. В Белгородской области раннецветущие хризантемы начинают цвести в конце августа и в сентябре [17]. В Беларуси, Молдове, Белгородской области РФ хризантемы цветут раньше, чем в Сочи.

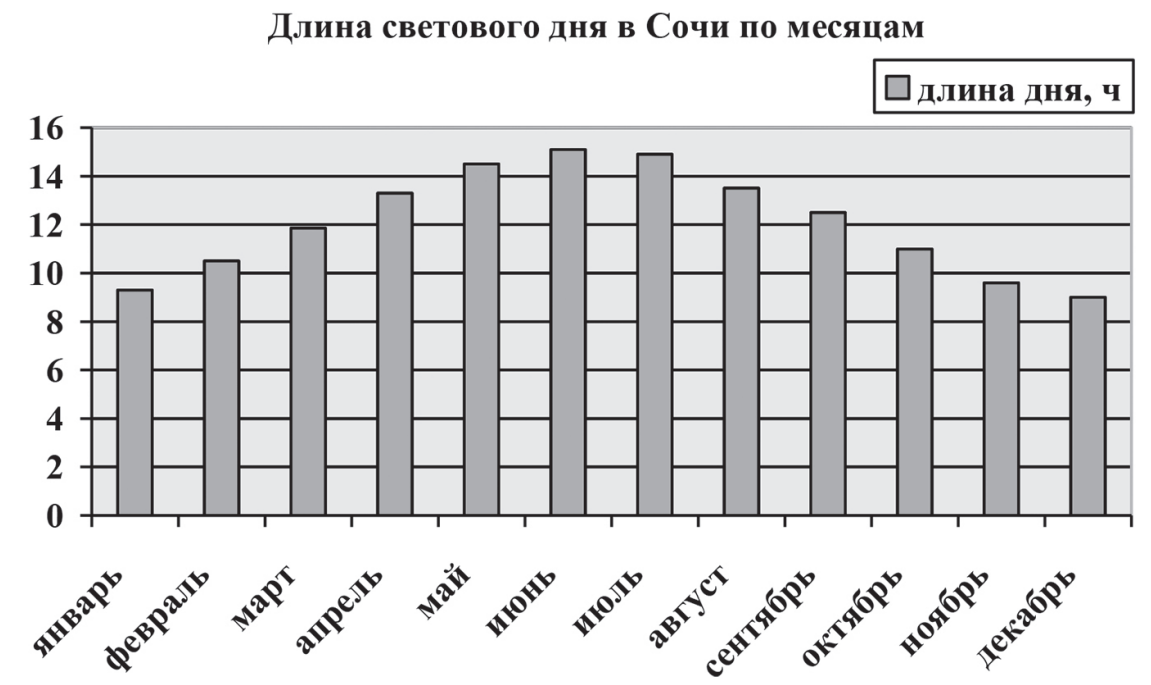

Рис. 1. Диаграмма продолжительности светового дня в г. Сочи по месяцам

Заключение. Таким образом, анализ данных фенологических наблюдений исходного селекционного материала хризантемы садовой (Chrysanthemum $\times$ hortorum) коллекции ФИЦ СНЦ РАН, состоящий из 9 сортов и 7 гибридов позволил выделить три группы по срокам цветения:

- гибриды раннего срока цветения: Ж-116-2; К-104-1; Ж-10-4; И-181-1 - цветут с 18-25 октября по 15-22 ноября;

- сорта и гибриды среднего срока цветения: 'Zembla Lime’; ‘Annecy White'; 'Балун'; ‘Золотая Нива'; 'Tiger Red'; К-141-1; Ж-23-5 - цветут с 25-30 октября по 20-30 ноября.

- сорта позднего срока цветения: 'Mona Lisa White'; 'Princess Amgard bronze'; 'Princess Amgard bronze’; ‘Этруско'; Ж-108-2 - цветут с 29 октября - 5 ноября по 20-26 декабря. 
В условиях защищённого грунта бутонизация у ранних гибридов и сортов начинается при длине дня 12-13 часов, у средних - при длине дня 11-12 часов. Для закладки бутонов поздним гибридам и сортам необходим световой день 11 часов.

Установлено, что продолжительность цветения изучаемых образцов составляет более 20 дней, наибольшая у сортов 'Балун', 'Золотая Нива', ‘Annecy White’ и гибридов К-141-1, Ж-23-5.

\section{Библиографический список}

1. Агафонов Н.В., Мамонов Е.В., Иванова И.В., Ващенко М.А., Воробьев Б.Н., Скакова А.Г. Декоративное садоводство. - М.: Колос, 2003. - С.167-170. - ISBN. 5-10-003500-5.

2. Адрианов В.Н. Хризантемы в теплице // Гавриш. - 2004. - № 5. - С. 35-37. ISSN: 2074-0468.

3. Войняк И.В. Влияние температуры на сроки цветения хризантем // Ботанические чтения - 2013: мат. науч.-практ. конф., Ишим, 13 мая 2013 г. - Ишим: филиал ТюмГУ, 2013. - С. 24-26.

4. Дядченко О.В. Состояние и тенденции развития цветоводства в СССР и за рубежом - Обзор МС. - М.: Агропроминформ, 1989. - 51 с.

5. Казанкова Л.С. Технология выращивания хризантем в совхозе «Декоративные культуры» // Организация производства и научно-технический прогресс в промышленном цветоводстве и декоративном цветоводстве: тез. докл. республ. научно-техн. конф., Кишинёв, 24-26 июня 1981 г. - Кишинёв: МССР, 1981. - С. 10-12.

6. Клемешова К.В., Габуева Т.Ю. Основные декоративные признаки сортов Chrysanthemum $\times$ hortorum Bailey в условиях влажных субтропиков России // Субтропическое и декоративное садоводство. - 2020. - Вып. 73. - С. 43-50. doi: 10.31360/2225-3068-2020-73-43-50.

7. Методика проведения испытаний на отличимость, однородность и стабильность хризантемы (многолетней) Chrysanthemum spec. // Офиц. бюл. Гос. Комис. РФ по испытанию и охране селекц. достижений, 1995. - № 3. - 12 с.

8. Мохно В.С. Создание новых сортов хризантемы на юге России // Субтропическое и декоративное садоводство. - 2014. - Вып. 50. - С. 186-192. - ISSN 2225-3068.

9. Мохно В.С., Братухина Е.В. Селекция цветочных культур на юге России // Плодоводство и ягодоводство России. - 2006. - Вып. 15. - С. 82-84. - ISSN 2073-4948.

10. Мохно В.С., Братухина Е.В. Цветочно-декоративные культуры. Хризантема // Программа Северо-Кавказского центра по селекции плодовых, ягодных, цветочнодекоративных культур и винограда на период до 2030 г. - Краснодар: СКЗНИИСиВ, 2013. - 202 c. - ISBN 9725982720962.

11. Мохно В.С., Братухина Е.В., Якушина Л.Г. Селекция хризантемы в условиях влажных субтропиков Краснодарского края // Субтропическое и декоративное садоводство. - 2017. - Вып. 63. - С. 78-85. - ISSN 2225-3068.

12. Недолужко А.И. Род Chrysanthemum L. на юге российского Дальнего Востока: интродукционные возможности, ресурсы изменчивости, селекция, сохранение генофонда : автореф. дис. ... д-ра с.-х. н. - Мичуринск: Наукоград. - 2010. - 42 с.

13. Недолужко А.И. Хризантемы для Приморья. - Владивосток: БСИ ДВО РАН, 2004. - 49 c. - ISBN 5-7442-1375-9. 
14. Рындин А.В. Агроэкологические аспекты садоводства влажных субтропиков России. - Сочи: ВНИИЦиСК, 2016. - 260 с. - ISBN 978-5-904533-29-8.

15. Рындин А.В., Келина А.В., Слепченко Н.А., Клемешова К.В. Перспективы импортозамещения в декоративном садоводстве субтропической зоны России // Субтропическое и декоративное садоводство. - 2015. - Вып. 55. - С. 19-26. - ISSN 2225-3068.

16. Стевенсон Т. Хризантемы / пер. с англ. Н.С. Зарахович, под ред. М.П. Нагибиной. - М.: Сельхозгиз, $1937-62$ с.

17. Стецович А.С., Сорокопудова О.А. Адаптация видов и сортов хризантем (Chrysanthemum L.) при интродукции на юго-запад Черноземья // Вестник Кра«сГАУ. - 2010. - Вып. 8. - С. 24-28. - ISSN 1819-4036.

18. Траутвейн К.С., Клемешова К.В. История изучения хризантемы (Chrysanthemum $\times$ hortorum Bailey) во Всероссийском научно-исследовательском институте цветоводства и субтропических культур // Субтропическое и декоративное садоводство. - 2018. - Вып. 64. - С. 26-33. - doi: 10.31360/2225-3068-2018-64-26-33.

19. Цеханович С.В. Состав и структура коллекции хризантемы индийской (Chrysanthemum indicum L.): мат-лы междунар. науч. конф., посвященной 85-летию Центрального ботанического сада НАН Беларуси, Минск, 6-8 июня 2017 г. - Минск: Медисонт, 2017. - 504 с.

20. Шмыгун В.Н. Хризантемы. - М.: Наука, 1972. - 116 с.

\title{
FLOWERING PERIODS OF GARDEN CHRYSANTHEMUM (CHRYSANTHEMUM $\times$ HORTORUM) CULTIVARS AND HYBRIDSIN THE CONDITIONS OF THE CAUCASUS BLACK SEA COAST
}

\author{
Yakushina L. G. \\ Federal Research Centre \\ the Subtropical Scientific Centre of the Russian Academy of Sciences, \\ Sochi, Russia, e-mail: -vishnya584@yandex.ru
}

The stages of anthodiums flowering were investigated in 9 cultivars and 7 hybrids of garden chrysanthemum (Chrysanthemum $\times$ hortorum Bailey) collected at FRC SSC RAS. All the studied chrysanthemum forms were divided into three groups according to the stages of anthodiums development: early-flowering (flowering from October 18-25 to November 15-22); average-flowering (flowering from October 2530 to November 20-30), late-flowering (flowering from October 29 - November 5 to December 20-26). the longest flowering periods were identified in the forms: 'Balun', 'Etrusco', 'Annecy White', Zembla Lime', and K-141-1. In the conditions of the Caucasus Black Sea coast, chrysanthemums mainly bloom in the periods from midOctober to mid-December, and some ('Etrusco', 'Annecy White', Zh-108-2) bloom until the end of December, when the daylight duration becomes less than 11 hours. Buds initiation begins when the daylight is reduced to 12 hours. Chrysanthemum blooming also depends on the temperature factor.

Key words: garden chrysanthemum (Chrysanthemum $\times$ hortorum), daylight duration, temperature, flowering period, initial breeding material. 